\title{
Surgical Outcomes of Pediatric Humeral Supracondylar Fractures Treated By Posterior Approach and Triceps Splitting
}

\section{Omidi-Kashani $\mathrm{F}^{1}$, Hasankhani $\mathrm{EG}^{1 *}$ and Hasankhani $\mathbf{G G}^{2}$}

${ }^{1}$ Associate Professor of Orthopedic, Orthopedic Research Center, Imam Reza Hospital, Faculty of Medicine, Postal Code 913791-3316, Mashhad University of Medical Sciences, Mashhad, Iran

${ }^{2}$ Medical Student, Orthopedic Research Center, Imam Reza Hospital, Faculty of Medicine, Mashhad University of Medical Sciences, Mashhad, Iran

\begin{abstract}
Background: A significant number of complications that maybe occur with surgical treatment of humeral supracondylar fractures in children are approach related. In this study we tried to compare the outcome of triceps splitting (posterior approach) with other approaches.

Methods: Thirty six consecutive children with displaced Gartland Type III extension supracondylar fractures underwent open reduction and internal fixation in our university hospital from March 2005 to March 2011. They were divided into three groups on the basis of surgical approach; Group A (14 patients) posterior approach with triceps splitting, Group B (10patients) posterior approach with tongue shape flap, and Group C (12 patients) lateral, anterolateral, or medial approach.

Results: In group A, range of motion was graded as excellent in $71.43 \%$, good $21.43 \%$, and fair $7.14 \%$. In group $B$, the range of motion was excellent in $70 \%$, good $20 \%$, and fair $10 \%$. Deformity was observed in one patient $(10 \%)$. In group $C$ the range of motion of the elbow was excellent in $66.6 \%$, good $16.7 \%$, and fair $16.7 \%$. Deformity was seen in two $(16.7 \%)$ patients. Pin tract infection was seen in one patient in each group.

Conclusion: In surgical treatment of humeral supracondylar fracture with normal neurovascular state in children, due to its simplicity, greater exposure, lack of interference with vital structures, and better surgical outcome, the posterior approach particularly posterior triceps splitting method is advocated.
\end{abstract}

Keywords: Humerus; Pediatric; Supracondylar fracture; Posterior approach

\section{Introduction}

Supracondylar fractures of humerus in children are the most common pediatric elbow fractures that account for about $70 \%$ of elbow fractures [1-3]. These fractures are divided into two types; extension (98\%) and flexion (2\%) type. Regarding to the amount of displacement, the extension type is divided by Gartland into type I (without displacement), type II (with displacement but intact posterior cortex) and type III (with displacement and disruption of both cortices) [3,4]. Type III is a common cause of surgical treatment among children. Treatment usually consists of closed reduction and internal fixation (CRIF), but in some patients open reduction and internal fixation (ORIF) is required [5-9]. Surgical indications that are often mentioned include unsuccessful closed methods, severe displacement, pucker sign, severe ecchymosis in anterior part of elbow, vascular insufficiency (weak pulse, ischemic findings in the muscles of forearm) and open fractures $[7,10,11]$.

A significant number of complications that maybe occur with surgical treatment of these fractures are approach related. Open reduction can be performed through a posterior, lateral, medial, or anterior approach or a combination of these. The ideal approach should be safe, quick and associate with appropriate exposure of the fracture site. The purpose of this study is to evaluate the efficacy of posterior approach with triceps splitting is surgical treatment of pediatric supracondylar fracture and compare it with other approaches.

\section{Materials and Methods}

36 consecutive admitted children (27 male, 9 female) with supracondylar fracture type III underwent open reduction and internal fixation in our university hospital from March 2005 to March 2011.
The incidence of elbow fracture was twice in left side (24 versus 12). There were 35 extension-type injuries and one patient with flexion-type injury. The mean age was $6.2 \pm 3.4$ years (ranged; $2.5-14$ ). We divided them into three groups based on the surgical approach; Group A (14 patients) underwent posterior approach with triceps splitting, Group B (10 patients) posterior approach with tongue shape flap, and group C (12 patients) lateral, anterolateral, or medial approach.

Group A and B were operated while lying in prone or lateral decubitus position. We used the lateral position with the arm supported on a pillow. In Group C, the patients were placed in supine position. All fractures except two were closed. These two cases were belonged to the Group C. Two of the patients had preoperative radial nerve palsy that recovered completely in three months and one patient had vascular injury treated with anterior approach. In the patients treated with posterior approach, two pins were crossly inserted, while in other patients, these pins were inserted parallel. We placed distal ends of the pins outside of the skin to easily remove them later. A long arm

*Corresponding author: Ebrahim Ghayem Hasankhani, Associate Professor of Orthopedic, Orthopedic Research Center, Imam Reza Hospital, Faculty of Medicine, Postal Code 913791-3316, Mashhad University of Medical Sciences, Mashhad, Iran, Tel: +98 915313 1083; Fax: +98 511 8595023; E-mail: hasankhanie@mums.ac.ir, eghasankhani@yahoo.com

Received October 18, 2013; Accepted November 23, 2013; Published November 25, 2013

Citation: Omidi-Kashani F, Hasankhani EG, Hasankhani GG (2013) Surgical Outcomes of Pediatric Humeral Supracondylar Fractures Treated By Posterior Approach and Triceps Splitting. J Trauma Treat S4: 007. doi:10.4172/2167-1222. S4-007

Copyright: (c) 2013 Omidi-Kashani F, et al. This is an open-access article distributed under the terms of the Creative Commons Attribution License, which permits unrestricted use, distribution, and reproduction in any medium, provided the original author and source are credited. 
Citation: Omidi-Kashani F, Hasankhani EG, Hasankhani GG (2013) Surgical Outcomes of Pediatric Humeral Supracondylar Fractures Treated By Posterior Approach and Triceps Splitting. J Trauma Treat S4: 007. doi:10.4172/2167-1222.S4-007

Page 2 of 3

posterior splint in $90^{\circ}$ flexion was applied for three weeks. After that, the pins and splint were removed and active range of motion exercises started. Postoperative visits were carried out at 3,12 weeks and 12 months later to monitor the radiological and clinical recovery.

We used Gruber and Healy score to assess the functional (loss of motion) outcomes of the elbow (Table 1) [12]. Baumann's angle difference and bony union were assessed to evaluate the radiological outcome. Post surgical complications comprised compartment syndrome, nerve injury, vascular injury, pin tract infection, deformity (cubitus varus or valgus), myositis ossificans, and wound conditions. We used SPSS (Software Package for Social Sciences) program, version 11.5 for data analysis. $\mathrm{P}<0.05$ was considered as significant.

\section{Results}

We could follow-up all 36 cases for more than 12 months. The mean follow-up was $17.4 \pm 7.9$ months (ranged; 12 to 23 ). Surgical indications in our patients included unsuccessful closed reduction due to massive edema in 24 , delayed presentation more than three days in eight, and pucker sign and severe ecchymosis on anterior surface of elbow in four patients.

Functional scores according to Gruber and Healy in three groups are shown in Table 2. The amount of difference in loss of elbow motion among three groups were similar and comparable $(\mathrm{p}<0.001)$. Our complications comprised pin tract infection (one patient in each group, all resolved with local wound care and oral antibiotic therapy), cubitus valgus (one case in Group B and one in Group C), and cubitus varus (one in Group C). Other complications like myositis ossificans or Volkmann's contracture did not happened in any cases.

\section{Discussion}

The main aim of the treatment of displaced Gartland type III humeral supracondylar fractures in children is to gain a perfect anatomical reduction, full range of motion and cosmetically acceptable extremity [13-16]. Closed reduction and percutaneous pinning of these fractures has been accepted as a choice treatment in reaching these goals by many authors $[17,18]$. Proponents of this approach state that fewer complications such as infection, myositis ossificans and loss of movement occur occurred in closely treated patients $[11,19]$.

Inadequate reduction can produce deformities such as cubitus varus (the most common), cubitus valgus, malrotation, angulation (in sagittal plane) or translation, which can cause functional disability $[20,21]$. To avoid these complications, some authors have advocated open reduction and pinning as an alternative treatment [22]. Therefore, open reduction and internal fixation are strongly recommended in patients with unfavorable closed reduction, neurovascular compromise, open fractures, severe displacement, pucker sign, or severe ecchymosed on anterior surface of the elbow.

Literature reveals that in management of type III supracondylar fracture in children, an unfavorable closed attempt is the most common indication for open surgery. Proponents of surgical approach believe that closed anatomical restoration of the severely displaced fractures is difficult to achieve (Figures 1 and 2). Repeated manipulations may also result in neurovascular injury, joint stiffness, or myositis ossificans [22]. Many studies demonstrated that ORIF produces the results as good as closed approaches and is associated with very low complications [23].

There are four different approaches that can be used in these fractures; medial, lateral, posterior and anterior. Opponents of ORIF believe that open surgery can cause more adverse events like loss of

\begin{tabular}{|c|c|}
\hline Grade & Loss of elbow range of motion \\
\hline Excellent & $0-4$ \\
\hline Good & $4-8$ \\
\hline Fair & $8-12$ \\
\hline Poor & $>12$ \\
\hline
\end{tabular}

Table 1: Gruber and Healy Score.

\begin{tabular}{|c|c|c|c|}
\hline Functional Score & Group A (\%) & Group B (\%) & Group C (\%) \\
\hline Excellent & $10(71.4)$ & $7(70)$ & $8(66.6)$ \\
\hline Good & $3(21.4)$ & $2(20)$ & $2(16.7)$ \\
\hline Fair & $1(7.2)$ & $1(10)$ & $2(16.7)$ \\
\hline Poor & 0 & 0 & 0 \\
\hline
\end{tabular}

Table 2: Functional scores in three groups.

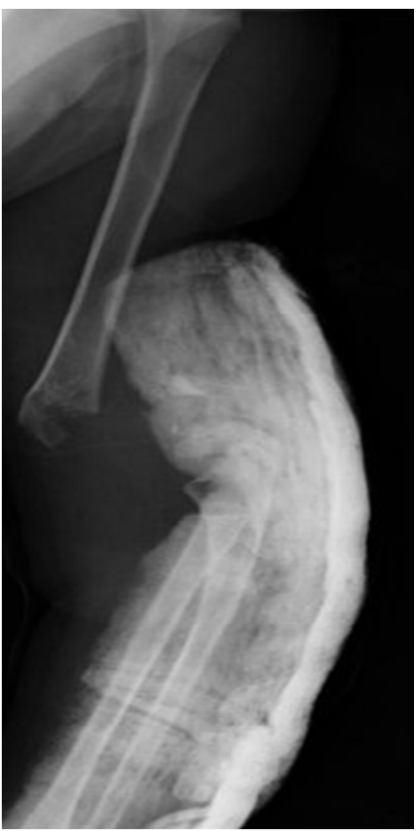

Figure 1: Humeral surcondylar fracture in a 4 years old girl with severe displacement referred to our hospital.
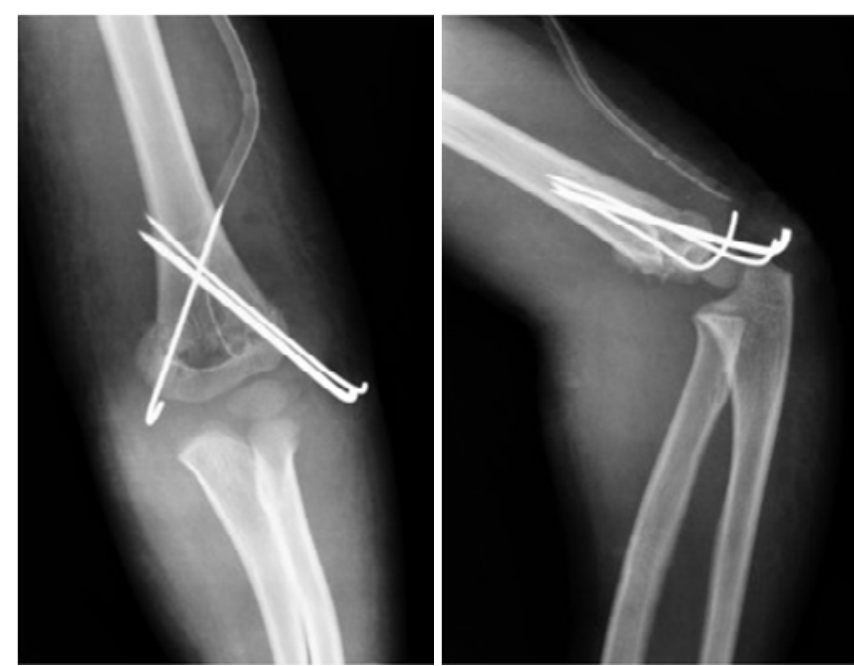

Figure 2: After open reduction and internal fixation with triceps splitting posterior approach. 
Citation: Omidi-Kashani F, Hasankhani EG, Hasankhani GG (2013) Surgical Outcomes of Pediatric Humeral Supracondylar Fractures Treated By Posterior Approach and Triceps Splitting. J Trauma Treat S4: 007. doi:10.4172/2167-1222.S4-007

motion, myositis ossificans and infection [24]. The most common complication of ORIF in surgical treatment of supracondylar fracture in children is loss of elbow joint motion. This complication is usually quoted to be more prevalent in posteriorly treated children [24-27]. In this study, we could not find a significant difference between elbows motions in the posteriorly treated patients and other approaches.

In this study, although the mean follow-up period was remarkable, the study itself has some withdrawals. The number of cases was not significant and therefore we could not maneuver on the numerical difference significantly. Moreover, our study design was retrospective and inevitably the usual limitations of a retrospective study are also applicable to this study. In conclusion, we propose posterior approach particularly posterior triceps splitting method in surgical treatment of Type III humeral supracondylar fracture with normal neurovascular state in children. Our seasons for this comprise its simplicity, greater exposure, lack of interference with vital structures, and better surgical outcome. In cases with vascular injury or open fractures with anterior wound, anterior approach is preferred.

\section{Acknowledgment}

The authors thank Dr. Ebrahimzadeh $\mathrm{MH}$, the head of Orthopaedic Research Center, Mashhad University of Medical Sciences, for his assistance in this study.

\section{References}

1. Mangwani J, Nadarajah R, Paterson JM (2006) Supracondylar humera fractures in children: ten years' experience in a teaching hospital. J Bone Joint Surg Br 88: 362-365.

2. Omid R, Choi PD, Skaggs DL (2008) Supracondylar humeral fractures in children. J Bone Joint Surg Am 90: 1121-1132.

3. Mihrano Tachdjian (2008) pediatric orthopedics $\left(3^{\text {rd }}\right.$ edn), Philadelphia, W Saunders Co.

4. Celiker O, Pestilci FI, Tuzuner M (1990) Supracondylar fractures of the humerus in children: analysis of the results in 142 patients. J Orthop Trauma 4: 265-269.

5. Kazimoglu C, Cetin M, Sener M, Aqus H, Kalanderer O (2009) Operative management of type III extension supracondylar fractures in children. In Orthop 33: 1089-1094.

6. Flynn JC, Zink WP (1993) Fractures and dislocations of the Elbow. Pediatric fractures. A practical approach to assessment and treatment. Baltimore, Williams \& Wilkins.

7. Skaggs DL, Hale JM, Bassett J, Kaminsky C, Kay RM, et al. (2001) Operative treatment of supracondylar fractures of the humerus in children. The consequences of pin placement. J Bone Joint Surg Am 83: 735-40.

8. Larson L, Firoozbakhsh K, Passarelli R, Bosch P (2006) Biomechanical analysis of pinning techniques for pediatric supracondylar humerus fractures. $J$ Pediatr Orthop 26: 573-578.

9. Kaewpornsawan K (2001) Comparison between closed reduction with percutaneous pinning and open reduction with pinning in children with closed totally displaced supracondylar humeral fractures: a randomized controlled trial. J Pediatr Orthop B 10: 131-137.

10. Eberhardt O, Fernandez F, Ilchmann T, Parsch K (2007) Cross pinning of supracondylar fractures from a lateral approach. Stabilization achieved with safety. J Child Orthop 1: 127-133.

11. Koudstaal MJ, De Ridder VA, De Lange S, Ulrich C (2002) Pediatric supracondylar humerus fractures: the anterior approach. J Orthop Trauma 16: 409-412.

12. Gruber MA, Healy WA 3rd (1996) The posterior approach to the elbow revisited J Pediatr Orthop 16: 215-219.

13. Ersan O, Gonen E, Arik A, Dasar U, Ates Y (2009) Treatment of supracondylar fractures of the humerus in children through an anterior approach is a safe and effective method. Int Orthop 33: 1371-1375.

14. Sharma H, Taylor GR, Clarke NM (2007) A review of K-wire related complications in the emergency management of paediatric upper extremity trauma. Ann R Coll Surg Engl 89: 252-258.

15. Otsuka NY, Kasser JR (1997) Supracondylar Fractures of the Humerus in Children. J Am Acad Orthop Surg 5: 19-26.

16. Pretell-Mazzini J, Rodriguez-Martin J, Andres-Esteban EM (2010) Does open reduction and pinning affect outcome in severely displaced supracondylar humeral fractures in children? A systematic review. Strategies Trauma Limb Reconstr 5: 57-64.

17. Oh CW, Park BC, Kim PT, Park IH, Kyung HS, et al. (2003) Completely displaced supracondylar humerus fractures in children: results of open reduction versus closed reduction. J Orthop Sci 8: 137-141.

18. Mulhall KJ, Abuzakuk T, Curtin W, O'Sullivan M (2000) Displaced supracondylar fractures of the humerus in children. Int Orthop 24: 221-223.

19. Ozkoc G, Gonc U, Kayaalp A, Teker K, Peker TT (2004) Displaced supracondyla humeral fractures in children: open reduction vs. closed reduction and pinning. Arch Orthop Trauma Surg 124: 547-551.

20. Sadiq MZ, Syed T, Travlos J (2006) Management of grade III supracondylar fracture of the humerus by straight-arm lateral traction. Int Orthop 31: 155-158.

21. Turhan E, Aksoy C, Ege A, Bayar A, Keser S, et al. (2008) Sagittal plane analysis of the open and closed methods in children with displaced supracondylar fractures of the humerus (a radiological study). Arch Orthop Trauma Surg 128 739-744.

22. Kotwal PP, Mani GV, Dave PK (1989) Open reduction and internal fixation of displaced supracondylar fractures of the humerus. Int Surg 74: 119-122.

23. Cramer KE, Devito DP, Green NE (1992) Comparison of closed reduction and percutaneous pinning versus open reduction and percutaneous pinning in displaced supracondylar fractures of the humerus in children. J Orthop Trauma 6: 407-412.

24. Aktekin CN, Toprak A, Ozturk AM, Altay M, Ozkurt B, et al. (2008) Open reduction via posterior triceps sparing approach in comparison with closed treatment of posteromedial displaced Gartland type III supracondylar humerus fractures. J Pediatr Orthop B 17: 171-178.

25. Sibly TF, Briggs PJ, Gibson MJ (1991) Supracondylar fractures of the humerus in childhood: range of movement following the posterior approach to open reduction. Injury 22: 456-458.

26. Barlas K, Baga T (2005) Medial approach for fixation of displaced supracondylar fractures of the humerus in children. Acta Orthop Belg 71: 149-153.

27. Gennari JM, Merrot T, Piclet B, Bergoin M (1998) Anterior approach versus posterior approach to surgical treatment of children's supracondylar fractures: comparative study of thirty cases in each series. J Pediatr Orthop B 7: 307-313.
This article was originally published in a special issue, Post Traumatic Stress Disorders handled by Editor(s). Dr. Agius M, University of Cambridge, UK 